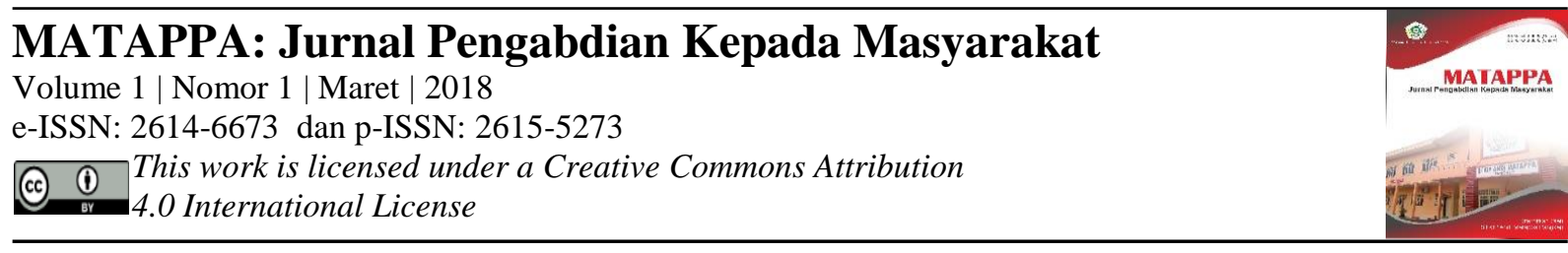

\title{
Penguatan Kemampuan Matematika Dasar Siswa SMA Melalui Kegiatan Matrikulasi
}

\section{Padrul Jana}

\begin{tabular}{ll}
\hline \hline Keywords : & ABSTRAK \\
Matematika Dasar; & $\begin{array}{l}\text { Tujuan kegiatan matrikulasi ini adalah untuk } \\
\text { meningkatkan kemampuan matematika dasar siswa SMA } \\
\text { Matrikulasi. }\end{array}$ \\
& agar ketika proses belajar mengajar di level berikutnya \\
& tidak merasa kesulitan. Metode yang digunakan dalam \\
Corespondensi Author & kegiatan ini melalui pretest, pemberian materi dan latihan \\
Matematika, Universitas PGRI & soal, postest dan terakhir evaluasi kegiatan. Hasil dari \\
Yogyakarta & kegiatan ini adalah meningkatnya pemahaman matematika \\
Jl. PGRI I Sonosewu No. 117 & dasar siswa sebesar 48,5\%, serta hasil akhir menunjukan \\
Yogyakarta Daerah Istimewa & siswa yang lulus kriteria ketuntasan minimal sebesar \\
Yogyakarta 55182 Indonesia & 51,4\%.
\end{tabular}

History Artikel

Received: 24-01-2018

Reviewed: $10-02-2018$

Revised: 02-03-2018

Accepted: 10-03-2018

Published: $30-03-2018$

\begin{abstract}
ABSTRAK
Tujuan kegiatan matrikulasi ini adalah untuk meningkatkan kemampuan matematika dasar siswa SMA agar ketika proses belajar mengajar di level berikutnya kegiatan ini melalui pretest, pemberian materi dan latihan soal, postest dan terakhir evaluasi kegiatan. Hasil dari kegiatan ini adalah meningkatnya pemahaman matematika dasar siswa sebesar 48,5\%, serta hasil akhir menunjukan $51,4 \%$.
\end{abstract}

\begin{abstract}
The aim of the matriculation is to improve the basic mathematics skills of high school students in order to ease the learning process in the next level. The method of this research is started with pretest, explaining material, exercise, postest and the last one in evaluation.The result of this activity is the increase of basic mathematics comprehension of the students which was 48,5\% and the final result showed that student who passed the criterion of minimum mastery were $51,4 \%$.
\end{abstract}

\section{PENDAHULUAN}

Sekolah Menengah Atas (SMA)

Muhammadiyah 3 Yogyakarta merupakan salah satu dari sekian banyak sekolah swasta di Yogyakarta. Secara umum sekolah swasta di kota Yogyakarta memperoleh peserta didik berkemampuan di bawah sekolah negeri. Hal ini dikarenakan siswa yang mendaftar di sekolah swasta merupakan siswa yang tidak tertampung di sekolah negeri ketika seleksi penerimaan peserta didik tahun ajaran baru. Kondisi tersebut tak terkecuali pada SMA Muhammadiyah 3 Yogyakarta, rerata nilai ujian nasional peserta didik yang masuk SMA Muhammadiyah 3 Yogyakarta berkisar 240 dari 4 mata pelajaran yaitu matematika, IPA, bahasa Indonesia dan
}

bahasa Inggris. Padahal rerata nilai minimum masuk SMA Negeri yang ada di kota Yogyakarta berkisar 350. Gap yang begitu mencolok mengakibatkan perbedaan signifikan pada kemampuan peserta didik antara sekolah swasta dan negeri, terutama kemampuan peserta didik pada mata pelajaran matematika. Di sisi lain matematika merupakan cabang ilmu yang dipelajari di semua tingkat satuan pendidikan. Matematika merupakan pelajaran yang penting karena merupakan ratu dan sekaligus pelayan dari segala ilmu. (Armianti, Yani, Widuri, \& Sulistiawati, 2016). Matematika juga salah satu ilmu pengetahuan dasar atau basic science berperan dalam meningkatkan kemampuan generasi penerus bangsa melalui pengembangan 
pola pikir dan daya nalar (Jana, 2017), hal ini menunjukkan pentingnya matematika dalam kehidupan.

Kondisi tersebut memaksa sekolah swasta harus memutar otak, bagaimana cara meningkatkan kemampuan peserta didik pada tahun ajaran baru dengan tujuan ketika proses belajar mengajar dimulai peserta didik sudah memiliki kemampuan matematika dasar secara merata sehingga akan mempermudah pemahaman matematika pada tingkatan sekolah menengah atas. Salah satu cara untuk mengatasi permasalahan di atas adalah dengan kegiatan matrikulasi mata pelajaran matematika. Kegiatan matrikulasi mata pelajaran matematika bagi kelas $\mathrm{X}$ (siswa baru) sebagai upaya program terobosan yang mempunyai sisi positif bagi siswa-siswi dalam peningkatan mutu pembelajaran (Ali, 2014). Kegiatan matrikulasi penting dilaksanakan sebagai respon atas fakta-fakta yang ada demi terwujudnya proses pembelajaran yang mudah dan tujuan akhirnya siswa menguasai dan memahami (penguatan) secara utuh matematika dasar sehingga dapat meningkatan prestasi peserta didik.

Beberapa publikasi yang telah menerapkan kegiatan matrikulasi diantaranya (Susiaty, 2016) hasilnya Rata-rata nilai matrikulasi mahasiswa dengan kecerdasan interpersonal tinggi, kecerdasan interpersonal sedang maupun kecerdasan interpersonal rendah tergolong gagal. Kegiatan matrikulasi juga mampu meningkatkan hasil belajar kimia mahasiswa secara signifikan meningkat $76 \%$ (Syahputra, Daulay, \& Ridwanto, 2016). Hal ini diperkuat oleh penelitian (Rosliana, Permanasari, \& Sudargo, 2014) bahwa kegiatan matrikulasi penting untuk peserta didik dengan latar belakang kemampuan yang berbeda. Lebih jauh lagi kegiatan matrikulasi dapat digunakan untuk meningkatkan nilai TOEFL mahasiswa (Herwandar, Safryono, \& Haryono, 2012).

\section{METODE}

Metode yang digunakan pada kegiatan matrikulasi adalah sosialisasi kepada orangtua dan peserta didik mengenai alasan kegiatan, tujuan kegiatan dan manfaat kegiatan, pemberian pretest untuk mengetahui sejauh mana pemahaman peserta didik baru dalam menguasai konsep matematika dasar. Selanjutnya pemberian materi tambahan pada mata pelajaran matematika dasar secara intensif

dan latihan soal sesuai topik yang disampaikan. Materi tambahan ini adalah materi dasar seperti operasi dasar bilangan bulat, pecahan, desimal. Selain operasi dasar kegiatan matrikulasi ini juga diisi dengan materi mengenai pangkat, akar dan fungsi. Pemberian postest untuk melihat sejauh mana kemajuan yang telah dicapai pada kegiatan matrikulasi ini. Terakhir adalah evaluasi pelaksanaan kegiatan matrikulasi lebih jelas dilihat pada diagram alir berikut ini:

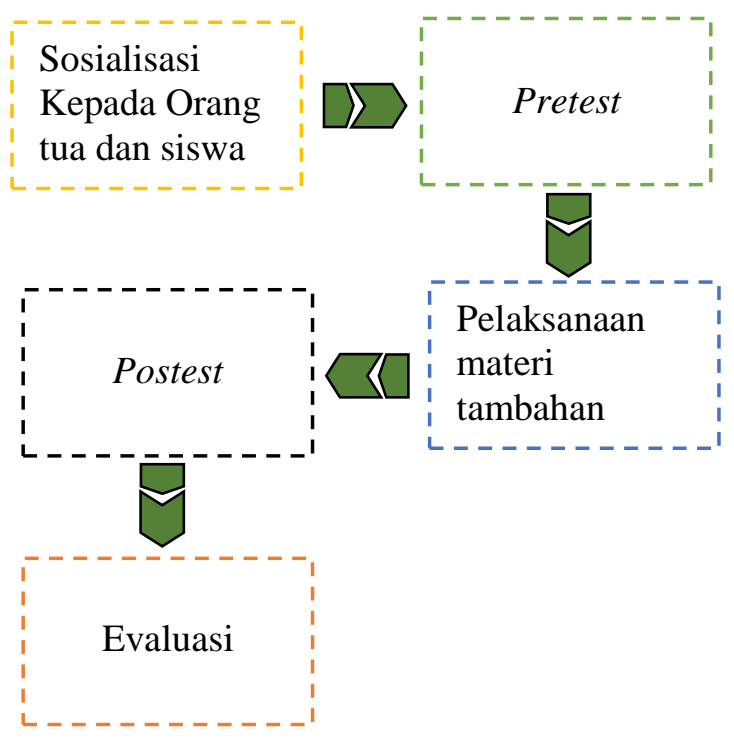

Gambar 1: Diagram alir kegiatan matrikulasi

\section{HASIL DAN PEMBAHASAN}

Pelaksanaan kegiatan matrikulasi yang dikemas dalam kegiatan pengabdian kepada masyarakat di diawali dengan pelaksanaan pretest tentunya setelah diadakannya sosialisasi. Pretest dilakukan untuk semua peserta didik kelas $\mathrm{X}$, untuk mengetahui kemampuan matematika dasar siswa dan siswi tersebut. tabel di bawah ini hasil pretest soal operasi bilangan bulat dan pecahan.

Tabel 1. Hasil pre test

\begin{tabular}{lccc}
\hline Skor & Rata-rata & $\begin{array}{c}\text { Std. } \\
\text { Deviasi }\end{array}$ & N \\
\hline Pre test & 53,46 & 12,54 & 35 \\
\hline \multicolumn{4}{c}{ Rata-rata hasil pretest } \\
bahwa kemampuan matematika dasar siswa \\
kelas X masih rendah. Hal ini sebetulnya sudah \\
dikonfirmasi dari rerata nilai UN siswa \\
pendaftar, fakta ini menjadi salah satu hal \\
diperlukannya penguatan kemampuan \\
matematika dasar siswa kelas X melalui \\
kegiatan matrikulasi.
\end{tabular}




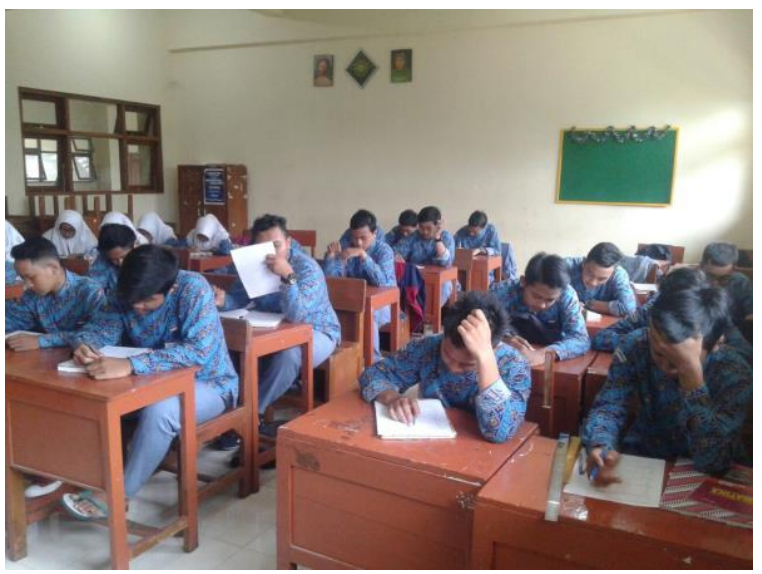

Gambar 2: Pemberian pretes

Pelaksanaan pemberian materi matematika dasar pada kegiatan matrikulasi dilaksanakan sebanyak 4 kali dalam sebulan, waktunya setelah pulang sekolah selama 1,5 jam per sesi. Pada peretemuan pertama materinya adalah operasi mengenai bilangan bulat, pembahasan mengenai operasi bilangan bulat sangat penting untuk menunjang kemampuan dasar matematika. Pertemuan kedua mengenai operasi bilangan pecahan, siswa SMA Muhammadiyah 3 Yogyakarta memiliki latar belakang kemampuan yang sangat variatif sehingga masih banyak dijumpai siswa kelas $\mathrm{X}$ yang belum lancar dalam operasi bilangan pecahan baik penjumlahan, pengurangan, pembagian maupun perkalian. Pertemuan ketiga mengenai operasi bilangan desimal dilengkapi dengan perubahan bilangan dari pecahan ke desimal atau sebaliknya. Pertemuan terakhir mengenai pangkat dan akar di sisipi materi fungsi.

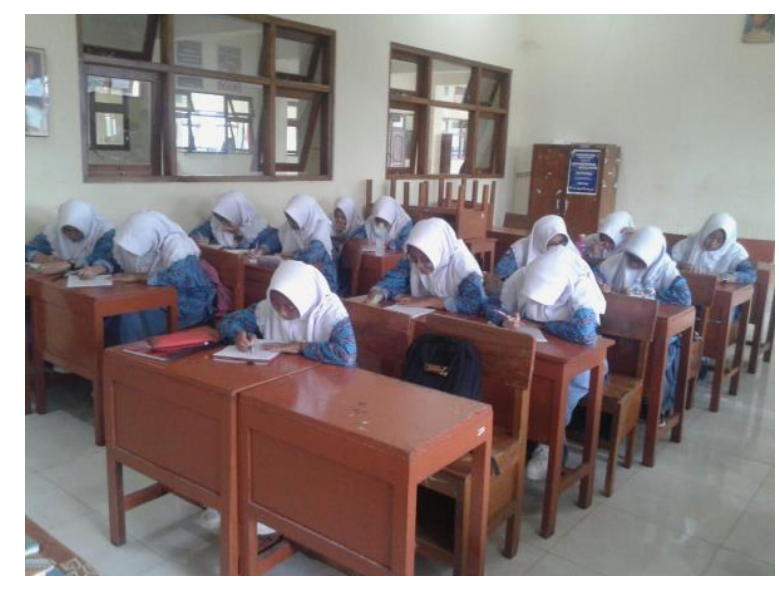

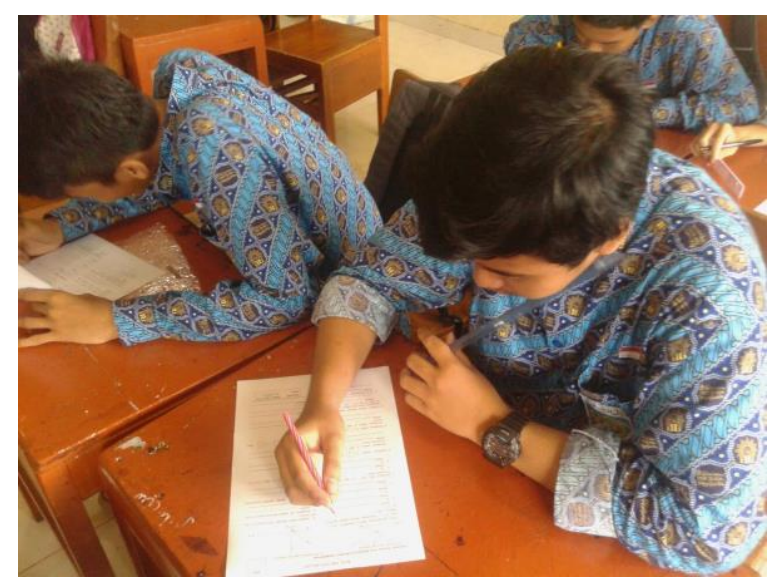

Gambar 3: Pemberian materi dan latihan soal

Hasil dari pertemuan pertama sampai terakhir diperoleh temuan yaitu masih banyak siswa kelas $\mathrm{X}$ yang masih rendah dalam penguasaan matematika dasar, dan ternyata dengan diadakannya kegiatan matrikulasi membuat mereka semangat mempelajari matematika dasar. Temuan lain, siswa terlihat antusias karena materi matematika dasar ini sangat mudah namun sebelumnya mereka belum kuasai. Pengabdi, mencoba mengkonfirmasi hasil kegiatan tersebut dengan melakukan postest dengan tujuan untuk mengetahui sejauh mana efek dari kegiatan matrikulasi dari sisi pemahaman matematika dasar. Hasil postest disajikan dalam tabel di bawah ini.

Tabel 2. Hasil postest

\begin{tabular}{cccc}
\hline Skor & Rata-rata & $\begin{array}{c}\text { Std. } \\
\text { Deviasi }\end{array}$ & N \\
\hline Postest & 73,31 & 10,01 & 35 \\
\hline
\end{tabular}

Dilihat dari hasil pretest dengan postest pemahaman matematika dasar siswa kelas $\mathrm{X}$ SMA Muhammadiyah 3 Yogyakarta secara ratarata meningkat dari 53,46 menjadi 73,31. Nilai siswa yang di atas batas kriteria ketuntasan minimal (KKM) ada 18 sisanya masih berada di bawah KKM dibandingkan dengan pretes kondisi ini jauh lebih baik. Persentase kenaikan siswa di atas KKM antara pretes dan postest sebesar $48,5 \%$, sedangkan persentase penurunan siswa yang berada di bawah KKM sebesar 48,7 $\%$ seperti di sajikan dalam tabel di bawah ini:

Tabel 3. Persentase kenaikan berdasar KKM

\begin{tabular}{cccc}
\hline Tes & $\begin{array}{c}\text { Persentase } \\
\text { Di atas } \\
\text { KKM }\end{array}$ & $\begin{array}{c}\text { Persentase } \\
\text { Di bawah } \\
\text { KKM }\end{array}$ & N \\
\hline Pretest & $2,8 \%$ & $97,2 \%$ & \multirow{2}{*}{35} \\
\hline Postest & $51,4 \%$ & $48,5 \%$ & \\
\hline
\end{tabular}


Terakhir dari rangkaian kegiatan ini adalah evaluasi. Beberapa catatan dalam kegiatan ini adalah kurangnya persiapan mengenai analisis instrumen test. Akan jauh lebih valid kalau instrumen test di uji validitas dan reliabilitasnya agar data yang masuk lebih akurat. Kemudian lembar kerja siswa baiknya di validasi oleh ahli agar keterbacaan, kepraktisan dan kevalidan lebih terjamin.

\section{SIMPULAN DAN SARAN}

Pengabdian ini bertujuan untuk meningkatkan atau menguatkan kemampuan matematika dasar siswa SMA Muhammadiyah 3 Yogyakarta. Hal ini didasari oleh fakta bahwa input siswa di sekolah ini tergolong rendah dilihat dari nilai UN SMP nya, juga melihat dari kemampuan siswa-siswi yang sangat beragam. Hasil dari pengabdian kepada masyarakat melalui kegiatan matrikulasi ini adalah meningkatnya pemahaman matematika dasar siswa dilihat dari hasil pretest dan postest yaitu naik sebesar 48,5\%.

Kegiatan matrikulasi sangat pentig dilaksanakan terutama pada sekolah dengan input siswa yang beragam dari sisi kemampuan apalagi dengan nilai ujian nasional yang relatif lebih rendah, sehingga ini menjadi solusi untuk menyiasati hal tersebut.

\section{DAFTAR RUJUKAN}

Ali, M. (2014). Strategi Manajemen Mutu Pelajaran Bahasa Arab Melalui Program Matrikulasi di Madrasah Aliyah Darut Taqwa Sengonagung Pasuruan. Jurnal Review Pendidikan Islam, 1(1), 41-53.

Armianti, Yani, I., Widuri, K., \& Sulistiawati.
(2016). Pengaruh Matematika GASING Gampang, ASyIk , dan menyenaNGkan ) pada Materi Perkalian Bilangan Bulat Terhadap Hasil Belajar Peserta Matrikulasi STKIP Surya. Kreano, 7(1), 74-81. https://doi.org/http://dx.doi.org/10.15294/k reano.v7i1.5012

Herwandar, R., Safryono, D. A., \& Haryono, P. Y. (2012). Evaluasi Program Matrikulasi "TOEFL" Mahasiswa Universitas Al Azhar Indonesia 2010/2011. Jurnal AlAzhar Indonesia Seri Humaniora, 1(3), 179-188.

Jana, P. (2017). Pembinaan Olimpiade Matematika Kelas VA CI SD Negeri Ungaran I Yogyakarta. J-Dinamika, 2(2), 125-128.

Rosliana, N., Permanasari, A., \& Sudargo, F. (2014). Gambaran Hasil Belajar Matrikulasi Kimia Kesehatan di Program Studi S1 Kesehatan Masyarakat STIKES Dharma Husada Bandung. Jurnal Pendidikan Matematika Dan Sains, 2(2), 187-194.

Susiaty, U. D. (2016). Eksperimentasi Matrikulasi Ditinjau dari Kecerdasan Interpersonal Mahasiswa Semester I Program Studi Pendidikan Matematika IKIP PGRI Pontianak. Jurnal Pendidikan Informatika Dan Sains, 5(1), 130-141.

Syahputra, R. A., Daulay, A. S., \& Ridwanto. (2016). Upaya Peningkatan Hasil Belajar Kimia Pada Mahasiswa Baru Prodi Farmasi 2015/2016 UMN Al-Washliyah. Jurnal Penelitian Pendidikan MIPA, 1(1), 27-33. 